\title{
Design for Assembly aplicado ao projeto de habitações em Light Steel Frame
}

\author{
Design for assembly applied to the design of Light Steel \\ Frame houses
}

\section{André Luiz Vivan José Carlos Paliari}

\section{Resumo}

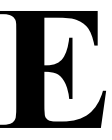

ste trabalho tem por objetivo principal a proposição de diretrizes para o desenvolvimento do Design for Assembly (DFA) para a produção de habitações unifamiliares. Tais diretrizes envolvem considerações a respeito da apresentação dos projetos e sobre a padronização das informações que definem a sequência de montagem dos principais elementos de uma edificação em LSF, visando a melhorar a construtibilidade dos projetos. Foi desenvolvido um exemplo de aplicação do DFA a um elemento de uma edificação em LSF. Este estudo foi baseado em conceitos obtidos na revisão bibliográfica, relacionados com a Engenharia Concorrente, Lean Design e DFA. Além disso, visando a destacar a importância na inovação de processos na construção, o atual contexto de projeto do LSF no Brasil foi caracterizado por meio de entrevistas com profissionais que têm utilizado esta tecnologia. O produto final deste artigo visa a contribuir para o avanço dos estudos a respeito do processo de projeto do LSF, além de promover o uso de conceitos pouco abordados na indústria da construção, como o DFA.

André Luiz Vivan Departamento de Engenharia Civil, Centro de Ciências Exatas e de Tecnologia

Universidade Federal de São Carlos Rodovia Washington Luís, km 235 São Carlos - SP - Brasil Caixa-Postal 13500 CEP 13565-905 Tel.: (16) 3306-6588 E-mail: andreluizvivan@gmail.com

José Carlos Paliari Departamento de Engenharia Civil, Centro de Ciências Exatas e de Tecnologia Universidade Federal de São Carlos Tel.: (16) 3351-8259 E-mail: jpaliari@ufscar.br

Recebido em 23/11/12 Aceito em 15/12/12
Palavras-chave: Design for Assembly. Engenharia Concorrente. Habitação. Light Steel Frame.

\section{Abstract}

The main objective of this paper is to propose guidelines for the development of Design for Assembly (DFA) applied to the design of single-family houses. Those guidelines involve considerations about design representation and the standardization of the information that defines the assembly sequence of the main elements of a LSF building, thereby improving the constructability of such projects. A practical application of DFA to an element of an LSF building was developed. This study was based on concepts obtained from the literature review, concerned with Concurrent Engineering, Lean Design, and DFA. Furthermore, in order to highlight the importance of DFA in the innovation of construction processes, the current context of LSF design in Brazil was characterized, based on interviews with professionals who have used this technology. The findings reported in this paper aim to contribute to the body of knowledge about the LSF design process, as well as to promote the use of concepts that are often overlooked in the Construction Industry, such as DFA.

Keywords: Design for Assembly. Concurrent Engineering. Housing. Light Steel Frame. 


\section{Introdução}

$\mathrm{Na}$ construção civil, o processo de projeto é uma atividade que, normalmente, apresenta muitas deficiências. Para a concepção de uma edificação há a necessidade de equipes multidisciplinares, que, geralmente, não existem dentro das empresas ou, se existem, atuam sem um modelo eficaz para a gestão de tal processo. Esse fato torna árdua a interação entre as várias disciplinas de projeto, e importantes informações a respeito da execução das tarefas acabam sendo negligenciadas ou depreciadas.

Nesse sentido, Farah (1996) afirma que, na construção civil brasileira, não há um planejamento prévio e sistemático da execução da obra, ou seja, os projetos não contemplam o local de produção (canteiro de obras) e as sequências das atividades de construção, o que gera constantes imprevistos, culminando com frequentes interrupções do trabalho na obra.

Pode-se dizer, então, que as práticas tradicionais de projeto na construção civil ainda são fundamentadas em hábitos que separam tal processo das atividades de produção. Assim, visando à modernização do setor, a indústria da construção civil começa a dar maior importância à necessidade de integração entre o processo de projeto e as atividades de construção (SONG; MOHAMED; ABOURIZK, 2009). Nesse sentido, Blacud et al. (2009) sugerem que as atividades das fases de projeto e produção podem ser associadas, o que possibilitaria melhor desempenho dos profissionais no canteiro de obras.

Tal sobreposição de atividades implica a necessidade de troca de informações entre os profissionais, o que origina um fluxo dessas informações. Esse fluxo normalmente não existe ou não é considerado no processo tradicional. Porém, conceitos como o Lean Design acabam derrubando tal característica, pois são fundamentados na Engenharia Simultânea (ES), conceitos estes que remetem à evolução dos projetistas no sentido de sistematizar-se o fluxo de informações entre as diversas atividades que dão suporte à produção (KOSKELA, 2000).

No caso da utilização do LSF, por ser um sistema construtivo pré-fabricado, o projeto torna-se a etapa fundamental para o sucesso do empreendimento, tanto sob o ponto de vista da engenharia quanto para o consumidor. Sendo um sistema com componentes industrializados, é imperativo que as atividades de execução no canteiro de obras sejam previamente concebidas durante o projeto, ou seja, a produção deverá ser projetada a fim de evitarem-se imprevistos e retrabalhos. No entanto, hoje no Brasil o projeto em LSF continua a ser desenvolvido à maneira descrita anteriormente por Farah (1996).

No que tange às condições ideais e necessárias de desenvolvimento projetual que amparam os conceitos de projeto em LSF, Prins e Kruijne (2008) afirmam que o projeto pode ser entendido como um processo de geração de informações e especificações que se inicia na concepção do produto e que se estende para a produção através de informações e subsídios. De maneira semelhante, Galle (2008) considera que o projeto é a produção de representações segundo uma ideia inicial que permite que um fabricante ou construtor produza determinado objeto.

Com essa linha de raciocínio, Ballard et al. (2001) utilizam a expressão inglesa Work Structuring (WS) para referirem-se a projetos que transmitam informações a respeito do sistema de produção, ou seja, projetar o modo como as atividades serão desenvolvidas. Para Howell e Ballard (1999), essa expressão reporta ao desenvolvimento do projeto dos processos de um empreendimento, que leva em consideração diversas atividades que dão suporte à obra, como as atividades de montagem.

Assim, tendo em mente o raciocínio por trás do WS e as características de montagem do LSF, considera-se plausível a aplicação de um tipo específico de projeto denominado Design for Assembly (DFA), que atende a uma parte dos requisitos do WS. Esse projeto será devidamente explicado neste artigo, mas, basicamente, o DFA contempla o projeto das atividades necessárias à produção, que para o LSF são definidas pela montagem dos componentes. Em resumo, o DFA é um tipo de projeto que visa à simplificação do processo de produção através da redução do número de componentes do produto, orientando e facilitando as atividades de montagem que utilizam tais peças (LAI; GERSHENSON, 2008).

Nesse contexto, o presente artigo propõe a utilização do DFA na conjuntura em que se inserem o processo de projeto e a produção de edificações unifamiliares de até dois pavimentos em LSF. Para isso, foram ropostas diretrizes que englobam considerações tanto a respeito da apresentação física dos projetos quanto a uma possível padronização das informações que identificam as sequências de montagem e os materiais e ferramentas necessários para tanto. Finalmente, é apresentado um exemplo de aplicação do DFA em um elemento de uma habitação típica em LSF. 


\section{Método de pesquisa}

\section{Estratégia de pesquisa}

Foram realizadas entrevistas com profissionais que utilizam o LSF nas fases de projeto e execução, com o intuito de ilustrar as atuais condições de uso e desenvolvimento desse sistema no Brasil.

Com relação às entrevistas, foi elaborado um roteiro principal, dividido em duas partes, que abordam tanto o processo de projeto de edificações em LSF quanto o seu processo de produção. Optou-se por abordar o processo de produção juntamente com os projetos para que fosse possível a percepção das consequências que as atuais práticas projetuais relativas ao sistema LSF ocasionam no canteiro de obras e, dessa forma, agregar as soluções para tais problemas nas diretrizes do DFA. Cabe ressaltar que as entrevistas foram gravadas com a devida autorização dos profissionais.

A primeira entrevista foi realizada com um profissional que atua na Companhia de Desenvolvimento Habitacional e Urbano (CDHU). A segunda entrevista realizou-se no Instituto de Pesquisas Tecnológicas (IPT) com profissional responsável pela qualidade dos componentes utilizados pelas construtoras nas residências construídas para a CDHU. A terceira entrevista foi realizada com profissional responsável pela gestão de uma obra da CDHU na cidade de Caraguatatuba, executada por uma construtora especializada em obras de LSF com sede na cidade de Curitiba. A quarta entrevista foi realizada com profissional de uma construtora, também especializada em LSF, com sede na cidade de São Paulo. E, por fim, a quinta entrevista foi realizada com profissional responsável pela área de projetos e execução de edificações em LSF em empresa sediada na cidade de Belo Horizonte.

No que diz respeito à relação entre conceitos, esta pesquisa propõe uma relação hierárquica entre os conceitos que amparam o uso do DFA. Esta hierarquia de conceitos foi necessária para que os dados coletados nas entrevistas fossem analisados com baseem um referencial teórico. Assim, foram consideradas as fronteiras de cada uma das teorias relacionadas aos diferentes conceitos, de maneira que, de acordo com a necessidade do estudo, os conceitos foram refinando-se, culminando com o DFA. Na Figura 1 é apresentada a relação entre os conceitos envolvidos, destacando-se os limites entre os mesmos.

Assim, as diretrizes propostas no presente estudo visa a preencher lacunas relacionadas ao projeto em LSF, com base nos resultados das entrevistas. Cabe destacar que o conteúdo das diretrizes tem como base os resultados das entrevistas e análise de projetos voltados para edificações em LSF. Tais diretrizes foram desenvolvidas com base no esquema da Figura 1, o que resultou na padronização das informações que devem constar no DFA de uma edificação em LSF.
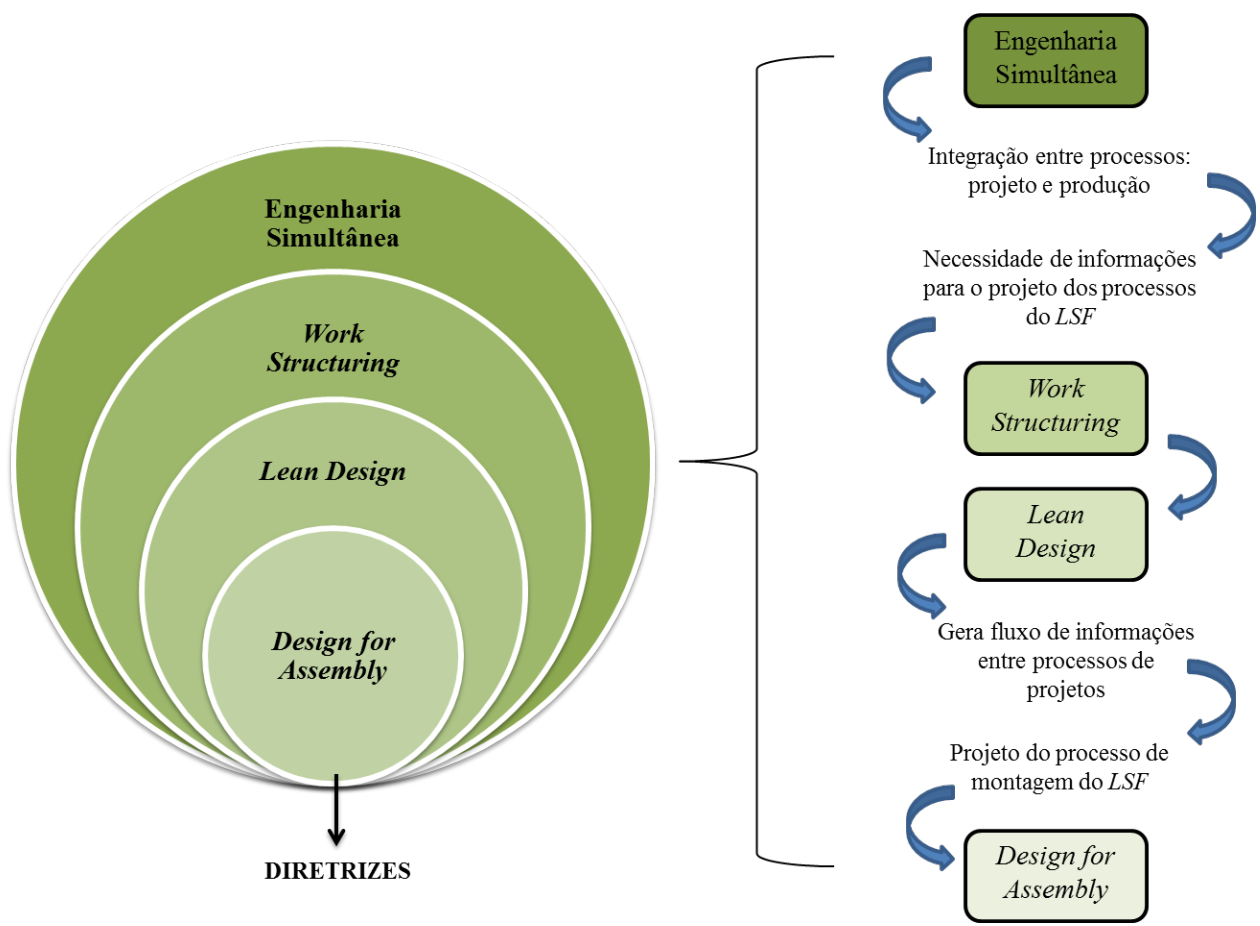

Figura 1 - Relação e limites entre conceitos obedecidos no artigo 
Além disso, é necessário destacar que este trabalho buscou estabelecer uma sólida base conceitual, visto que o referencial teórico adotado não é de uso corrente na construção civil.

\section{Delimitações}

O presente artigo limita-se à proposição de diretrizes para o desenvolvimento de um tipo específico de projeto voltado para a montagem de elementos edificações em LSF. Obviamente, a ideia de projetar-se o processo de produção pode ser aplicada em qualquer sistema construtivo. Porém, o estudo fica restrito ao LSF, pois este é um sistema considerado inovador no Brasil e carece de estudos acadêmicos nacionais voltados para questões relativas ao projeto. Além disso, o LSF difere das obras tradicionais no país, pois é um sistema que contempla atividades de montagem no canteiro de obras, o que abre espaço para a aplicação de novas práticas gerenciais, projetuais e executivas.

O reduzido número de entrevistas deve-se ao fato de o LSF não ser um sistema construtivo amplamente adotado no país, de maneira que apenas algumas poucas empresas o utilizam exclusivamente em seus empreendimentos. Além disso, cabe destacar que não é objetivo das entrevistas generalizar o atual estágio de desenvolvimento e produção do LSF no Brasil, mas auxiliar o desenvolvimento do produto deste artigo.

Quanto ao exemplo prático, este foi desenvolvido com o único intuito de mostrar a viabilidade das diretrizes propostas. O mesmo não foi aplicado em qualquer obra ou empresa e foi desenvolvido a partir da escolha aleatória de um elemento típico do sistema LSF.

\section{Relação entre conceitos}

\section{Considerações básicas a respeito do Light Steel Frame}

Indiscutivelmente, o LSF apresenta grandes vantagens produtivas justificadas pela préfabricação de seus componentes. Em uma análise global de um empreendimento em LSF, este pode representar um enorme ganho sob o ponto de vista técnico, mas que, comercialmente, ainda enfrenta barreiras culturais no Brasil. Economicamente, o LSF não é muito mais oneroso do que sistemas tradicionais, de maneira que o custo da unidade é diluído por sua rapidez de execução diante dos sistemas convencionais.

Gorgolewski (2006) lista algumas das vantagens do uso do LSF, como alta resistência, baixo peso (tanto da estrutura como dos demais componentes), grande precisão dimensional e resistência ao ataque de insetos. Além disso, os materiais utilizados são quase que totalmente recicláveis, o que contribui para a sustentabilidade da edificação, além de contribuir para o aumento do nível de especialização e qualidade da mão de obra, estabelecendo altos padrões de construção. Diante de tais vantagens, o LSF vem atraindo o interesse em muitos países nos últimos anos, principalmente para habitações unifamiliares (GORGOLEWSKI, 2006). Veljkovic e Johansson (2006) destacam as características industriais de construção do LSF, podendo ser projetado para atender a todos os requisitos funcionais característicos de edificações residenciais.

Cabe destacar, ainda, que as construções em LSF são caracterizadas por serem a "seco", pois, além de utilizarem estruturas de aço, também empregam, por exemplo, placas de gesso acartonado para vedação e lã de rocha como opção para isolamento térmico. Sob o ponto de vista do desenvolvimento técnico do LSF, tal sistema construtivo apresenta alto nível de pré-fabricação, montagens simples, pequenas tolerâncias, planejamento preciso e entregas just-in-time (BURSTRAND, 1998).

Essencialmente, o sistema LSF utiliza componentes pré-fabricados (toda a estrutura é pré-fabricada e deve ser projetada para solidarizar com a modulação da vedação). Dessa forma, podese dizer que as edificações em LSF são, obviamente se o processo de projeto fornecer subsídios para tanto, produzidas a partir da montagem dos componentes, excluindo-se a fundação, que ainda deve utilizar o concreto armado como principal material.

Em uma análise teórica a respeito do canteiro de obras, Vivan e Paliari (2011) garantem que o processo de produção de edificações em LSF é baseado, em sua essência, por atividades de conversão definidas pela montagem dos elementos. No contexto em que se insere o canteiro de obras em LSF, uma atividade de montagem difere da conversão de insumos, por ser entendida como sendo o ato de unir, por meio de dispositivos de conexão e fixação, como os parafusos, dois ou mais componentes pré-fabricados, com geometrias específicas que irão originar os elementos dos sistemas da edificação.

No entanto, para que tais características sejam desenvolvidas de maneira adequada, é necessário que o processo de projeto seja gerenciado por modelos de gestão que garantam a qualidade tanto para a engenharia dos processos quanto para o cliente. Assim, as características ideais para o 
processo de projeto devem ser guiadas por alguns princípios que permitam a eficácia na produção a partir da integração desta com o processo de projeto. Vários autores nacionais, como Crasto (2005) e Vivan (2011), consideram que o projeto das atividades de produção do LSF deva ser desenvolvido durante a concepção do empreendimento.

Uma das mais importantes estratégias da indústria moderna que também pode ser utilizada no processo de projeto da construção civil e, especificamente, no processo de projeto do LSF, a fim de se evitar a sequencialidade do mesmo, é a ES. Este é um conceito amplamente adotado na indústria de produtos seriados que promove a redução do tempo de desenvolvimento do produto, aumentando sua qualidade tanto sobre o ponto de vista da engenharia quanto para o cliente, com custos reduzidos.

Fundamentada em uma visão de fluxo de informações, a ES, de certa forma, pode ser formalizada, tendo em mente o processo de projeto, aplicando-se a ideia por trás do Lean Design. Assim, é coerente demonstrar a relação da ES com o Lean Design tendo em mente a necessidade de gerenciar-se o fluxo de informações originado pelo foco principal do estudo, que é a formulação de diretrizes para o desenvolvimento de projetos que orientem a montagem de elementos do LSF.

\section{Engenharia Simultânea}

Segundo Koskela (1992), a ES refere-se a uma estratégia essencialmente voltada para o projeto, sendo caracterizada por uma rigorosa análise dos requisitos iniciais que incorpora as restrições das fases subsequentes com controle sobre as possíveis mudanças que possam ocorrer. $\mathrm{O}$ autor mostra que os principais objetivos da ES sobre o processo de projeto é a redução do tempo de projeto, aumento de interações entre equipes e processos, e redução das alterações no produto. Esse raciocínio pode ser representado e mais bem detalhado pelo gráfico da Figura 2.

Nessa figura, nota-se que o ciclo de vida de projetos na ES é menor do que em comparação com projetos sequenciais, o que garante maior rapidez de início da produção. O gráfico também mostra que na ES há menos possibilidade de erros, visto que há fluxo de informações entre disciplinas de projeto, o que reduziria despesas e tempo despendido para revisões e correções.

Para Giudice, Ballisteri e Risitano (2009), a ES possibilita que o processo de desenvolvimento seja estruturado e administrado com base nas atividades de integração do processo de projeto, de forma que inclua, de maneira geral, a implementação de novos métodos e técnicas e a reorganização das atividades de desenvolvimento do produto, com a participação de uma equipe multidisciplinar de projeto, que atua em uma ampla gama de competências, visando a produtos funcionais de alta qualidade a custos baixos em um curto período.

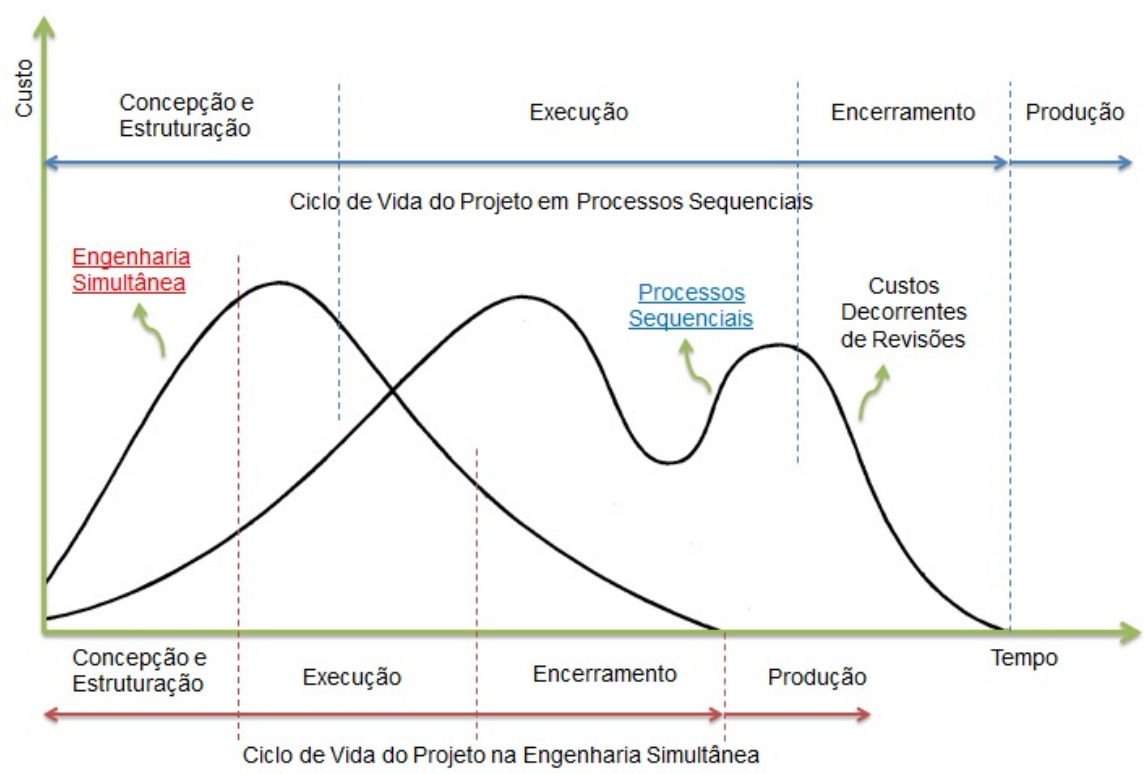

Figura 2 - Processo de projeto em processo sequencial comparado com processo simultâneo Fonte: adaptado de Kruglianskas (1993). 
No entendimento de Antaki, Schiffauerova e Thomson (2010), a ES é uma estratégia em que determinado número de tarefas é desenvolvido em paralelo, ou seja, de forma não linear, por membros de equipes e líderes de diferentes departamentos e locais, de forma que todos esses profissionais necessitem ter acesso às informações das mesmas fontes simultaneamente. Segundo os autores, a consideração do fluxo de informações proporcionada pela ES assegura maior e melhor nível de comunicação entre departamentos e, consequentemente, entre processos, o que reduz os custos e mudanças no projeto durante a produção.

Assim, é possível assegurar que a ES é uma estratégia de trabalho que pode ser utilizada em vários processos do empreendimento, mas que possui um foco principal no processo de projeto. No que diz respeito ao processo de projeto do LSF, a utilização da ES, como estratégia de atuação, torna-se especialmente importante, visto que todas as atividades necessárias para a construção da edificação devem ser estudadas, projetadas e coordenadas durante o processo de projeto, pois tal sistema construtivo é incompatível com imprevistos no canteiro de obras.

Nesse sentido, o uso da ES permite que as atividades de montagem inerentes ao sistema LSF sejam devidamente detalhadas, revelando ao operário o modo correto de execução, as sequências de montagem, bem como as interferências entre subsistemas, além da redução, ou até mesmo eliminação, de imprevistos (VIVAN; PALIARI; NOVAES, 2010).

Dessa maneira, a ES fornece as condições ideais e necessárias para o desenvolvimento de um tipo específico de projeto que contemple as sequências de montagem de elementos que utilizam peças préfabricadas, como ocorre com o LSF. Koskela (2007), no contexto dos conceitos da ES, corrobora tal afirmativa, assegurando que o uso de ferramentas para tais conceitos e a mudança das práticas características do processo de projeto tradicional permitiram o desenvolvimento de algumas soluções, e, entre elas, destaca-se o Design for Assembly (DFA).

\section{Lean Design}

No Lean Design o processo de projeto é abordado sob três aspectos, conversão, fluxo e valor. No entanto, como afirmam Freire e Alarcón (2002), somente o aspecto da conversão das informações é modelado, gerido e controlado pelos profissionais da construção civil, sendo o fluxo de informações e valor, inerente das mesmas, habitualmente ignorado. Nesse sentido, os referidos autores afirmam que a ES muito contribui com esses dois aspectos (fluxo e valor), pois propicia um gerenciamento sistemático deles.

Koskela, Huovila e Leinonen (2002) afirmam que os três aspectos do Lean Design são baseados tanto na visão tradicional de projeto (conversão) quanto na visão da ES (fluxo e valor). Por exemplo, Ballard e Koskela (1998) apontam que, no gerenciamento de projetos, a visão do fluxo de informações tem como principal objetivo a eliminação de desperdícios por meio da redução de retrabalhos, formação de equipes multidisciplinares e liberação de informações em menor quantidade para as tarefas seguintes. Os autores mostram que, para isso, é necessária a redução das incertezas, a integração entre projetos e parcerias entre profissionais. Assim, para que haja a consideração e o gerenciamento do projeto como fluxo de informações, é necessário que as equipes que desenvolvem tal projeto estejam inseridas nos conceitos da ES, no sentido da forma como as atividades são desenvolvidas por essas equipes, conforme os conceitos apresentados anteriormente.

Em pesquisa realizada na Suécia a respeito da construção de residências unifamiliares com sistemas construtivos pré-fabricados, Stehn e Bergström (2002) afirmam que a estratégia de projeto adotada com relação a essas obras levava em conta a troca de informações entre o processo de projeto, os clientes (com suas necessidades e requisitos) e o processo de produção dessas casas, ou seja, gerenciamento do fluxo de informações visando à eficácia da construção e à satisfação do cliente (Lean Design). Porém, o gerenciamento do fluxo de decisões só foi possível porque o processo de projeto estava inserido no contexto de atuação da ES, de maneira que esta possibilitou a integração e a troca de informações entre projetos e a produção (STEHN; BERGSTRÖM, 2002).

Segundo Jørgensen (2006), o Lean Design não possui uma definição formal específica e pode ser utilizado de diversas formas, com o intuito de se aplicar a filosofia lean. O mesmo autor também afirma que os principais estudos e práticas atuais a respeito do assunto são voltados para questões de interações entre disciplinas de projeto e entre o projeto e o processo de produção. Antaki, Schiffauerova e Thomson (2010) deixam claro que estratégias ou conceitos de fluxo de informações utilizados no processo de projeto (como o Lean Design) são muito bem modelados pelos conceitos da ES.

Essas afirmações apontam a intenção deste artigo em mostrar que, para projetarem-se os processos de montagem (DFA), informações devem fluir entre zonas conceituais e práticas, que se refinam a 
partir de condições de contorno obtidas de acordo com a necessidade do profissional. Por exemplo, o gerenciamento do fluxo de informações visa, principalmente, à redução ou à eliminação das atividades desnecessárias, o que reduz custos e tempo de trabalho; dessa forma, o foco principal do conjunto (ES e Lean Design) estaria voltado para o projeto das atividades estritamente necessárias na construção.

Nesse caso, surgem alguns tipos específicos de projeto que, dentro da filosofia do Lean Design e da ES, poderiam ser classificados como sendo os meios pelos quais esses dois conceitos podem ser aplicados na integração entre o processo de projeto e a produção. Essencialmente, tais projetos contemplam a construtibilidade do produto, ou seja, as informações originadas visam à delimitação das atividades essencialmente indispensáveis à construção, buscando a otimização entre as técnicas necessárias do sistema construtivo adotado com as condições do canteiro de obras e da mão de obra utilizada.

\section{Projetando os processos: Work Structuring}

Considerando a promoção de informações a respeito de operações e processos, entende-se que o projeto de uma edificação em LSF deveria prever e estabelecer quais seriam as atividades necessárias a sua montagem. A composição desse tipo de informação também envolve considerações a respeito de ferramentas, operários e tempos relativos à montagem de cada elemento em questão. Nesse contexto, o WS apresenta uma conceituação pertinente às necessidades projetuais do LSF, pois, segundo Ballard et al. (2001), seu propósito fundamental é projetar o sistema de produção, que se estende de um nível global de organização estruturada a partir de decisões a respeito de como o trabalho físico será realizado.

Segundo Tsao (2005), o WS não é uma ideia nova. O conceito por trás do termo é utilizado há muito tempo por profissionais de área correlata, porém a autora revela que não existe a formalização de uma metodologia científica que suporte seu desenvolvimento sistemático. Para Ballard (2000), o WS representa o nível mais fundamental do processo de projeto. $\mathrm{O}$ autor considera que a aplicação desse conceito promove 0 desenvolvimento do projeto de operações e processos, alinhados com o projeto do produto, além do que o WS promove esforços para que o projeto seja orientado para a divulgação de informações a respeito da montagem do produto.
Analisando os trabalhos de Ballard (2000, 2008), considera-se que o WS abrange quatro fases principais de um empreendimento desenvolvido, produzido e gerenciado em ambiente Lean. Tais fases compreendem: (a) project definition (definição do empreendimento); (b) lean design (projeto enxuto); (c) lean supply (suprimento enxuto); e (d) lean assembly (montagem enxuta).

No que tange ao processo de projeto, o referido autor afirma que o Lean Design insere-se diretamente no conceito do WS por meio de três etapas, garantindo o desenvolvimento delas. Tais etapas são distintas e relacionam-se por meio da interação e consequente fluxo de informação, sendo elas: design concepts (projeto conceitual), product design (projeto do produto) e process design (projeto do processo) (Figura 3). No caso de edificações em LSF, a etapa do process design pode ser desenvolvida com o uso do DFA, estando este, portanto, no contexto do Lean Design e, consequentemente, do WS, como demonstrado na Figura 3.

Parece haver indicações de que o DFA tem um ponto de inserção alinhado com os princípios da Lean Construction, especificamente no processo de projeto (WS). O esquema da Figura 3 indica que, estando o DFA dentro de uma etapa do Lean Design (Process Design), então, conceitualmente, os fluxos de informações para as fases posteriores do empreendimento estarão garantidos, tendo em vista que todo o processo é contornado pela ES.

Assim, como conceito final antes da elaboração das diretrizes, de acordo com a estratégia de pesquisa proposta, o presente estudo relaciona, a seguir, o DFA com o contexto teórico apresentado até o momento.

\section{Design for Assembly}

No contexto teórico do WS, o DFA emerge como um tipo de projeto que contempla uma das etapas do Lean Design, considerando o raciocínio de Ballard (2000, 2008). Desenvolvido pela indústria de produtos seriados, a origem do DFA reporta-se aos anos 60, quando as grandes indústrias de manufatura pregavam a ideia de que seus projetistas deveriam conhecer a fundo os processos de produção da empresa para que criassem projetos eficientes e efetivos. Porém, os projetos eram essencialmente voltados para a criação de partes individuais do produto, sendo pouco esforço intelectual destinado aos processos de fabricação das peças e montagem do produto final (KUO; HUANG; ZHANG, 2001). 


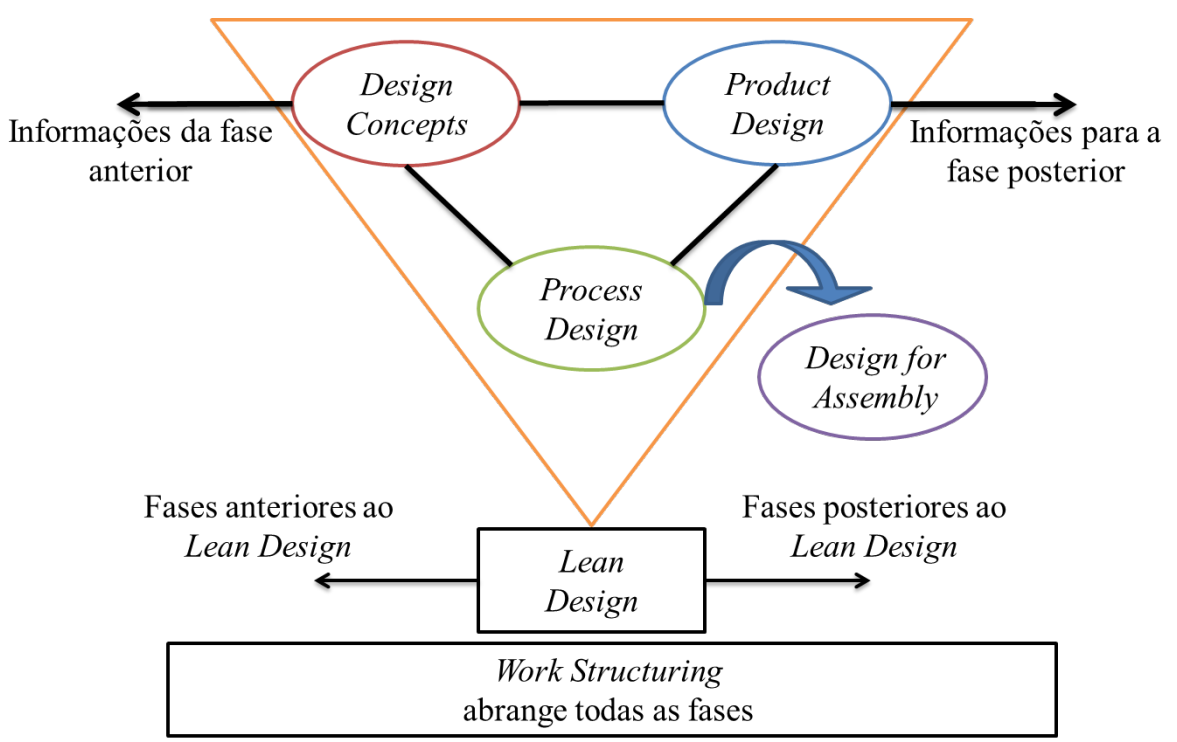

Figura 3 - Lean design conexo ao WS e DFA associado ao process design

Fonte: adaptado de Ballard (2008).

No meio acadêmico, os primeiros trabalhos a abordar o projeto como um processo capaz de definir as atividades específicas de montagem são de autoria de Boothroyd e Dewhurst, durante o final dos anos 70 e início dos anos 80, com destaque para o trabalho intitulado Design for Assembly, destes autores (KUO; HUANG; ZHANG, 2001; SCUR, 2009; MOTTONEN et al., 2009).

De acordo com Wu e O'Grady (1999), o principal objetivo do DFA é envolver as operações de montagem e atividades de suporte relacionadas, ou seja, projetar o processo de montagem. Aqui, claramente, evidencia-se que uma das etapas que compõem o Lean Design (neste caso, o process design) é cumprida com o uso do DFA; consequentemente, esse tipo de projeto insere-se no WS de um canteiro de obras de uma edificação em LSF.

Segundo Boothroyd, Dewhurst e Knight (2002), o DFA proporciona melhor eficácia na análise da facilidade de montagem dos produtos por meio dos projetos, fornecendo resultados rápidos e simples. Os autores afirmam ainda que o DFA deve ser de fácil entendimento, assegurar a coerência e integralidade durante a montagem das peças, evitar e até mesmo eliminar avaliações subjetivas com relação às atividades de montagem, identificar áreas problemáticas durante a produção e sugerir soluções alternativas visando à simplificação do produto e reduzindo os custos de produção. Uma característica marcante do DFA, tendo em vista todos os seus atributos, é sua representação gráfica. Nela, normalmente o componente ou elemento é representado em perspectivas explodidas, que mostram os componentes e seus locais de encaixe ou fixação.

Para Lai e Gershenson (2008), o uso do DFA tem por finalidade a simplificação do processo de projeto por meio da redução do número de partes que compõem o produto, facilitando seu manejo durante a produção. De acordo com os referidos autores, a partir do momento em que há projetos voltados para as atividades de montagem, é possível, portanto, que o desenvolvimento desses projetos resultem na simplificação da produção por meio da otimização de peças, componentes e, por consequência, das atividades de montagem. Nesse sentido, Khan (2008) afirma que o DFA proporciona o encurtamento do ciclo de produção, minimiza custos de desenvolvimento e garante uma transição segura, sem imprevistos, da fase de projeto para a fase de produção.

Dessa forma, analisando os conceitos apresentados, pode-se afirmar que o DFA é um tipo de projeto que visa definir as atividades e ferramentas necessárias durante a produção de um objeto que utilize peças pré-fabricadas, ou seja, uma análise inicial no contexto em que se insere a construção civil mostra que utilizar o DFA durante o processo de projeto significa projetar a montagem do produto. Como consequência de seu uso, o processo de desenvolvimento do projeto cria possibilidades de evolução na forma do produto, visto que um dos objetivos do DFA é simplificar e reduzir o número de peças aserem utilizadas.

Assim, com todo o raciocínio proposto, considerase que o uso do DFA na construção civil ganha maior fundamentação, tendo como base uma estrutura de atuação e desenvolvimento baseada 
nos moldes propostos pela Lean Construction. As diretrizes propostas neste artigo, para o desenvolvimento do DFA, estão inseridas no processo de projeto por meio de uma das etapas que compõem o Lean Design. Tais diretrizes correspondem a uma parcela do que é definido com o WS do processo de produção de uma edificação em LSF, caracterizada pela montagem de seus elementos.

\section{Resultados das entrevistas}

As entrevistas foram guiadas por questões que abordam tanto o processo de projeto de edificações em LSF quanto o processo de produção, focando as atuais práticas entre os profissionais. Os temas principais correspondem aos conceitos relacionados à ES, projetos voltados para os processos (como o DFA), planejamento da produção e atividades de construção no canteiro de obras de LSF. De certa forma, esperava-se que os resultados fossem próximos aos apresentados logo abaixo, de maneira que as entrevistas comprovassem o sentimento inicial da pesquisa.

Com relação à produção das edificações em LSF, constatou-se que a mão de obra é especializada e altamente dependente de seu conhecimento técnico e experiência prática para a execução dos serviços, e eventuais decisões a serem tomadas no canteiro de obras. O tempo de conclusão da produção é relativamente curto com relação às obras tradicionais; por exemplo, toda a montagem da estrutura de uma edificação de LSF de 100,00 m² pode ser concluída em um prazo de 10 dias, segundo dados fornecidos pelos entrevistados.

No que diz respeito aos projetos desenvolvidos para o LSF, estes seguem as práticas usuais adotadas nas obras convencionais, ou seja, há uma sequência hierárquica de serviços que se inicia com a arquitetura da edificação. De acordo com entrevistados, durante essa sequência de desenvolvimento, os projetistas dificilmente trocam informações entre si e entre os profissionais do canteiro de obras, de forma que a compatibilidade entre sistemas e subsistemas da edificação fica a cargo da empresa construtora.

Em uma das visitas, constatou-se que importantes decisões executivas tiveram de ser tomadas durante a montagem e fixação de subsistemas nos elementos estruturais. Tais decisões resultaram no corte de componentes estruturais para que fosse possível a fixação das peças que compunham o subsistema. Isso revelou claramente que o processo de projeto é sequencial, e da maneira descrita por Freire e Alárcon (2002); as informações contemplaram apenas aspectos de conversão das informações, focando o projeto dos produtos, anulando qualquer integração e consequente fluxo de informação entre diferentes projetos e processos.

Diante disso, não se observaram evidências do uso do WS no empreendimento, assim como não foram verificadas ou notadas evidências do uso da ES. De certa forma, isso contribui para a alta dependência da experiência do operário, uma vez que o desenvolvimento do DFA tornaria o processo de montagem uma atividade apenas mecânica ao trabalhador, e não tão intelectual (focando a atividade do operário). No caso descrito, a falta do projeto do processo de montagem daquele elemento em questão resultou em uma decisão não condizente com as boas práticas de montagem preconizadas para o LSF, podendo, inclusive, acarretar em manifestações patológicas futuras.

Cabe destacar que, nas entrevistas, não ficou em destaque nas empresas, em sua estrutura de projeto, o uso de quaisquer conceitos que foram apresentados para o desenvolvimento de seus produtos, seja por desconhecimento ou por comodidade em relação ao que é tradicionalmente praticado. De maneira geral, as obras em LSF são produzidas com projetos básicos que, de certa forma, são um pouco mais detalhados do que os utilizados para obras convencionais; porém esses projetos são compostos, essencialmente, do projeto de arquitetura e do projeto estrutural.

Nas entrevistas constatou-se que a atual modelagem do processo de projeto do LSF não cumpre com a demanda por informações das atividades do processo de produção, de maneira que, usualmente, surgem muitas dúvidas por parte dos operários no canteiro de obras. Assim, na tentativa de reduzir-se a demanda por informações executivas, na sequência, são apresentadas as diretrizes para a elaboração do DFA voltado para o LSF, com o intuito de promover mudanças na forma de projetar-se com tal sistema construtivo, visando melhor desempenho da produção.

\section{Aplicação do DFA no Light Steel Frame}

\section{Diretrizes para desenvolvimento}

Tendo em vista as teorias apresentadas até aqui, além dos resultados das entrevistas, considera-se possível que o DFA seja aplicado ao processo de projeto de edificações em LSF. De fato, este artigo apresenta as diretrizes que, no atual estágio de pesquisa e entendimento dessa ferramenta na construção civil, entende-se como as mais plausíveis de ser aplicadas. 
A rigor, o desenvolvimento e a aplicação das diretrizes tomam como pré-requisito essencial e inicial o fato de que as empresas e os profissionais estão inseridos em um contexto de atuação modelado pela ES. Isso é justificado, pois o DFA é estruturado com informações que contemplem desde o projeto do produto (painéis, tesouras, lajes, etc.) até informações a respeito da maneira como esse produto será montado, além da indicação de ferramentas, materiais e tempos de montagem, diferenciando-o dos demais projetos.

Uma vez que a ES promove a interação entre diferentes etapas do ciclo de vida da edificação, cabe ao WS delegar e gerenciar as equipes responsáveis pelo desenvolvimento de cada item das diretrizes (uma vez que envolvem processos diferentes). Inevitavelmente, isso gera um fluxo de informações que, nesse caso em específico, é analisado pelas fronteiras operacionais do Lean Design. Assim, uma vez que o Lean Design comporta projetos relativos aos processos, representados pela subetapa do Process Design, o DFA e, por conseguinte, as diretrizes encontram auxílio operacional e embasamento conceitual adequado para seu uso, desenvolvimento e evolução.

Assim, o conteúdo apresentado mostra como o DFA voltado para edificações em LSF deverá ser elaborado, tendo em vista uma primeira abordagem de uso desse tipo de projeto na construção civil brasileira.

As diretrizes aqui propostas contemplam quais informações deverão constar no DFA, a fim de que os conceitos de tal ferramenta sejam satisfeitos no contexto em que se insere o processo de produção de edificações em LSF. Dessa forma, considera-se que os projetos voltados para a montagem de edificações em LSF devam ser elaborados a partir das seguintes diretrizes:

(a) para o início do desenvolvimento do DFA, é imprescindível que estes sigam rigorosamente as informações geradas por cada disciplina de projeto, obedecendo aos tipos de perfis que serão utilizados, às dimensões, aos materiais utilizados e à disposição dos elementos e componentes;

(b) com relação aos aspectos físicos gerais do DFA, é conveniente que se utilizem pranchas com papéis no formato A3 (se as dimensões da estrutura em questão assim permitirem) e, se possível, papel no formato A4, para que os profissionais do canteiro de obras tenham facilidade na consulta e manejo dos projetos;

(c) tendo em vista a utilização de pranchas em formatos A4 e A3, os DFA devem ser organizados em um Caderno de Montagem organizado por um índice. As pranchas e as informações textuais deverão ser impressas no sentido "paisagem";

(d) no Caderno de Montagem, as pranchas em papel A3 deverão ser dobradas de maneira que se igualem ao tamanho do papel A4, com a impressão no sentido "paisagem";

(e) com relação ao índice do Caderno de Montagem, sugere-se que este seja organizado a partir de um conteúdo estruturado em:

- listagem geral de materiais necessários e seus respectivos quantitativos;

- listagem geral de ferramentas necessárias;

- equipamentos de proteção individual necessários;

- planta de identificação dos painéis; e

- diretrizes e detalhes gráficos para a montagem de cada sistema da edificação.

(f) considerando a planta de identificação dos painéis, esta deverá ser estruturada da seguinte forma:

- desenho com a disposição final de fixação dos painéis (estruturais e de vedação);

- no desenho com a disposição final dos painéis deverão ser colocadas cotas, que indicarão o comprimento de cada painel;

- nesta planta, cada painel deverá ser identificado por um símbolo estruturado pela combinação de um retângulo com um triângulo;

- neste símbolo deverá ser informado, no retângulo, se o painel é estrutural ou de vedação e o tipo de vedação que deverá receber. No triângulo deverá ser informado o número do painel;

- a palavra "estrutural", para se adequar ao símbolo, deverá ser abreviada "Est.". E a palavra "vedação", pelo mesmo motivo, deverá ser abreviada "Ved.";

- as palavras que identificam o material da vedação também serão abreviadas e deverão estar entre parênteses, como se segue: OSB - (OSB); Gesso Acartonado - (GA); Placa Cimentícia - (PC);

- nos painéis externos, a face voltada para fora da edificação deverá conter a descrição de qual tipo de revestimento será utilizado, como pintura, siding vinílico, madeira, ou qualquer outro material que cumpra com as exigências de um elemento ou componente de revestimento externo; e

- os números de identificação deverão ser contínuos e crescentes no sentido horário.

(g) cada representação gráfica do DFA (em cada prancha) deverão conter: 
- desenhos, em três dimensões, obrigatoriamente em perspectiva explodida, desenvolvidos, no mínimo, na escala 1:50, de maneira que a perspectiva adotada permita a visualização de todos os componentes da estrutura e da sequência de montagem. Os desenhos deverão representar da maneira mais fiel possível as peças que serão utilizadas para a composição da estrutura em questão, de maneira que fique claro ao profissional do canteiro de obras a posição final de instalação. Esses desenhos deverão ser estruturados da seguinte forma:

-- cada peça que compõe a estrutura em questão deve ser representada de maneira que tais peças estejam dispostas para indicar tanto a sequência de montagem quanto a posição correta de fixação;

-- como o desenho é feito em vista explodida, a posição correta de fixação deve ser mostrada por uma linha tracejada, que deverá ligar as peças que devem ser conectadas;

-- nas extremidades das linhas tracejadas, devem ser colocadas letras minúsculas do alfabeto, com o intuito de eliminar possíveis dúvidas a respeito de quais peças devem estar conectadas entre si, facilitando o encaixe;

-- ao longo das linhas tracejadas deverá constar qual o tipo de parafuso que deve ser utilizado para tal conexão e quantidade necessária para isso.

Sugere-se a adoção de letras minúsculas do alfabeto grego $(\alpha, \beta$, etc.) para a identificação de cada tipo de parafuso no desenho, precedidas dos números que correspondem à quantidade utilizada em cada fixação;

-- cada peça que compõe o elemento estrutural deverá ser nomeada, e sugere-se o seguinte código (Equação 1):

$\mathrm{Xy} \mathrm{C}-\mathrm{n}(\mathrm{Z})$

Onde:

Xy: abreviação para a classificação do tipo da peça (guia, montante, etc.);

C: sequência de utilização da peça dentro de sua classificação;

$\mathrm{n}$ : ordem de montagem $(1,2,3, \ldots, \mathrm{n})$; e

(Z): tipo da seção do perfil ou material que compõe a peça.

- carimbo de informações contendo:

-- título do projeto que deve ser relativo à estrutura que está sendo representada;

-- legenda para a decodificação de códigos que deverão ser utilizados para a identificação das peças;
-- lista de ferramentas exclusivas para a produção da estrutura em questão;

-- lista de parafusos que serão utilizados bem como a quantidade total prevista de uso de cada um, ou outro material necessário para a fixação de peças;

-- quantidade de operários necessários para a atividade proposta, bem como a especialidade de cada um;

-- tempo previsto para a conclusão da produção da estrutura representada na prancha, fornecendo o dia e o horário de início e conclusão do serviço;

-- o local de produção da estrutura (dependendo do leiaute do canteiro de obras); e

-- o meio de transporte do elemento até seu local de fixação.

(h) juntamente com o desenho em vista explodida deverá estar representado o desenho do elemento concluído, se possível, na mesma direção da perspectiva adotada para as sequências de montagem. Neste desenho deverão constar as principais distâncias entre componentes;

(i) além da representação gráfica principal do elemento, também deverá ser feito um desenho em perspectiva explodida, que mostra o posicionamento correto dos parafusos que irão fixar os componentes (se este for o caso):

- neste desenho deverão ser representados os componentes (assim como o parafuso em questão) em suas posições de parafusamento, além da posição em que o parafuso deverá ser fixado por meio de uma linha tracejada que se estenderá até o ponto de fixação;

- o desenho do parafuso deverá ser identificado com uma das letras gregas, como proposto anteriormente, bem como a quantidade necessária;

- deverão ser colocadas, no mínimo, duas cotas (uma horizontal e uma vertical) que demarquem a posição de fixação dos parafusos;

- deve-se indicar quantas vezes a operação demonstrada irá se repetir no elemento em questão; e

- não é necessário mostrar a sequência de atividades, já que tais informações já estarão no desenho principal.

(j) no caso de elementos que se repetem, identicamente, por várias vezes na edificação e em que as atividades de montagem são exatamente as mesmas (como as tesouras), deve-se indicar no desenho a quantidade de vezes que a montagem deverá se repetir;

(k) eventualmente pode ser necessário que elementos, nas condições em que se inserem as 
tesouras, por exemplo, sofram modificações em virtude da arquitetura da cobertura. Assim, no carimbo do desenho deverá ser indicado o tipo de tesoura que está sendo montada, atribuindo-se letras maiúsculas do alfabeto;

(1) cada prancha deverá ser antecedida ou precedida de informações textuais (diretrizes específicas), que deverão interpretar o desenho, fornecendo:

- a sequência de produção por meio das atividades que devem ser executadas;

- ferramentas necessárias para cada atividade; e

- como cada componente deverá ser fixado para que a estrutura seja formada.

(m) no caso da montagem das tesouras (se assim o for), deverá ser indicado na prancha o número de vezes que essa montagem deverá se repetir, estando, obviamente, em consonância com o cálculo estrutural.

A seguir, está representado um exemplo prático de aplicação das diretrizes anteriormente descritas. O exemplo inicia-se com as informações textuais específicas para a montagem do elemento em questão. Nesse caso, será utilizado como exemplo um painel não estrutural em LSF para uma edificação habitacional unifamiliar, que contém uma abertura para a fixação de uma esquadria qualquer. Cabe destacar que o exemplo não representa um painel que foi utilizado em qualquer obra, sendo desenvolvido com medidas arbitrárias e literais apenas para exemplificação do que foi proposto neste artigo.

\section{Exemplo prático}

A seguir, são apresentados os passos para a montagem de painel de vedação com esquadrias:

(a) de maneira geral, a montagem deve ser iniciada com a colocação da guia inferior na mesa de montagem e, logo após, deve ser fixado o primeiro montante, para que a ortogonalidade da estrutura seja garantida;

(b) para garantir a ortogonalidade entre o primeiro montante e a guia inferior, deve ser utilizado um medidor de ângulos digital para verificação do ângulo:

- um dos montantes fixado em uma das extremidades da guia deverá ser parafusado em simetria com o montante ao seu lado. Portanto, um dos montantes de uma das extremidades deve ser posicionado de maneira contrária aos demais, de forma que a primeira peça possa ser tanto a que será fixada de maneira contrária quanto a que será fixada na mesma sequência dos montantes internos.

(c) para garantir a distância entre montantes com precisão de até 3 casas decimais, deve ser empregado um medidor de distâncias a laser, a ser utilizado durante a fixação de cada montante;

(d) os montantes devem ser fixados sucessivamente, em quantidade de acordo com o projeto estrutural, até o final do painel (final da guia inferior). Após a colocação do último montante, deverá ser fixada a guia superior;

(e) após a fixação do montante imediatamente anterior à abertura para a esquadria, se a esquadria em questão for uma janela, deve ser fixado, junto à guia inferior, um montante de composição, que deverá ter a altura do peitoril para tal caixilho. A quantidade de montantes de composição é determinada pela largura do caixilho e pela modulação adotada para o LSF;

(f) ainda no caso de uma janela, após a colocação do montante de composição deve ser fixada a guia de abertura inferior;

(g) há várias configurações para a composição e forma das guias de abertura no sistema LSF, de forma que tais peças deverão ser montadas antes de sua instalação no painel;

(h) após a colocação da guia de abertura inferior, deverá ser fixada junto ao último montante fixado a guia de abertura superior, que, visando reduzir a diversificação de peças, deverá possuir a mesma forma adotada para a guia de abertura inferior;

(i) no mesmo eixo em que se encontra o montante de composição que forma o peitoril da janela (montante de composição inferior), e logo acima da guia de abertura superior, será fixado o montante de composição superior;

(j) imediatamente após a fixação da guia de abertura superior, deverá ser instalado o próximo montante estrutural, e assim sucessivamente, até o final do painel;

(k) após a colocação do último montante, deverá ser fixada a guia superior;

(1) para a fixação dos montantes nas guias inferior e superior, fixação de guias de abertura e montantes de composição, devem ser utilizados parafusos, que estarão discriminados no cálculo estrutural. Porém, normalmente são utilizados parafusos do tipo cabeça lentilha e ponta broca, que devem ser instalados por meio de uma parafusadeira elétrica;

(m) caso a esquadria em questão seja uma porta, os itens 5 e 6 devem ser desconsiderados. 
Com base nas atividades anteriormente descritas, está concebida na Figura 4 a representação gráfica do DFA, que contém todas as diretrizes de desenvolvimento propostas neste artigo. A representação foi elaborada com o uso de software CAD, com modelagem em 3D.

\section{Considerações finais}

Possuindo um enorme potencial de desempenho na produção, o LSF começa a ganhar atenção do mercado nacional, dos pesquisadores e de todos aqueles que buscam a racionalização da construção. Sendo um sistema amplamente aceito e utilizado em países desenvolvidos, sua essência de produção, de características extremamente práticas, exige que todo o processo de construção seja determinado durante o processo de projeto, que, por sua vez, está condicionado pelo rompimento com as práticas tradicionais na construção civil.

Nesse sentido, pode-se dizer que há uma premissa projetual no LSF baseada na necessidade de práticas de desenvolvimento paralelas entre as equipes responsáveis pelas diferentes disciplinas de projeto. Apesar de ser uma prática necessária e recomendada, ficou claro neste estudo que isso não é exercido pelos profissionais que trabalham com o LSF. No atual estágio de conhecimento aplicado aos projetos desse sistema nas empresas, nota-se que os profissionais insistem em práticas sequenciais e na omissão de alguns projetos que são essenciais para o sucesso do LSF.

Assim, foram abordadas importantes teorias; por ser um sistema que utiliza componentes préfabricados, foi sugerido que os projetos poderiam ser particularizados para um tipo mais específico, denominado Design for Assembly. A partir disso, foram elaboradas diretrizes com relação à estrutura de apresentação dos projetos do tipo DFA, bem como o conteúdo dos mesmos.

Cabe destacar que o desenvolvimento das diretrizes, bem como o desenvolvimento do DFA, é possível somente com a visão de fluxo de informações em um contexto operacional definido pelos conceitos da ES e gerenciado pelo WS, que, sendo referente à fase de projeto, é aplicado ao Lean Design e, consequentemente, ao process design (projeto do processo).

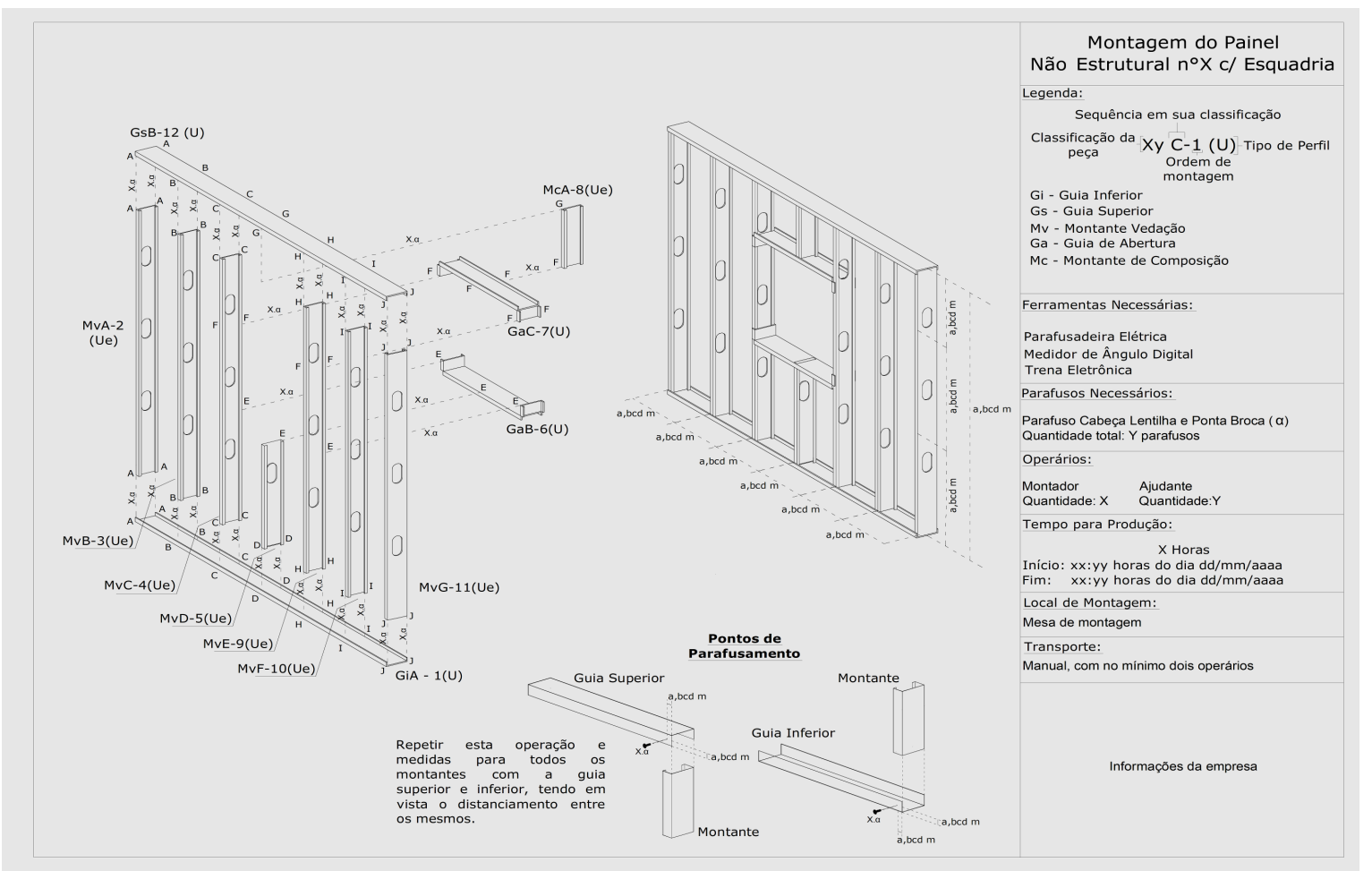

Figura 4 - Representação gráfica do DFA para um painel não estrutural com esquadria 
As diretrizes propostas visam promover e fomentar o uso de um novo tipo de projeto, ao menos para a construção civil, formalizado pelo DFA. Porém, é imprescindível destacar que a implementação das diretrizes e, consequentemente, do DFA somente se viabiliza a partir da compreensão de uma combinação de conceitos, como os apresentados neste artigo. Além disso, cabe destacar que o desenvolvimento físico do DFA pode ser altamente facilitado pelo uso de tecnologia da informação a partir de softwares BIM (Building Information Modeling). Tais softwares corroboram para os conceitos apresentados, pois mostram diversos processos da edificação, levando-se em conta interfaces, materiais, cronogramas, entre outras características peculiares do conceito.

Deve ficar claro que o principal propósito do DFA é a simplificação de componentes visando à redução do ciclo de produção e consequente redução de custos. Seu uso, proposto neste artigo, representa uma abordagem inicial dessa ferramenta aplicada em projetos de habitações unifamiliares em LSF, possibilitando o avanço no desenvolvimento dessa ferramenta na construção civil em estudos futuros.

\section{Referências}

ANTAKI, M.; SCHIFFAUEROVA, A.; THOMSON, V. The Performance of Technical Information Transfer in New Product Development. Concurrent Engineering: Research and Applications Journal, v. 18. n. 4, p. 291-301, 2010.

BALLARD, G. Lean Project Delivery System. Lean Construction Institute, white paper 8, 2000. Disponível em:

$<$ http://www.leanconstruction.org/pdf/WP_9_Proj ectDefinition.pdf $>$. Acesso em: 13 jul. 2012.

BALLARD, G. The Lean Project Delivery System: an update. Lean Construction Journal, v. 1, n.1, p. 1-19, 2008.

BALLARD, G.; KOSKELA, L. On the Agenda of Design Management Research. In: ANNUAL CONFERENCE INTERNATIONAL GROUP FOR LEAN CONSTRUCTION, 6., Guarujá, 1998. Proceedings... Guarujá: IGLC, 1998.

BALLARD, G. et al. Production System Design: work structuring revisited. In: ANNUAL CONFERENCE OF THE INTERNATIONAL GROUP FOR LEAN CONSTRUCTION, 9., Singapore, 2001. Proceedings... Singapore: IGLC, 2001.
BLACUD, N. A. et al. Sensivity of Construction Activities Under Design Uncertainty. Journal of Construction Engineering and Management, v. 135, n. 3, p. 199-206, 2009.

BOOTHROYD, G.; DEWHURST, P.; KNIGHT, W. Product Design For Manufacture and Assembly. $2^{\text {nd }}$. New York: Taylor \& Francis Group, 2002.

BURSTRAND, H. Light Gauge Steel Framing Leads the Way to an Increased Productivity For Residential Housing. Stockholm: Swedish Institute of Steel Construction, 1998.

CRASTO, R. C. M. de. Arquitetura e Tecnologia em Sistemas Construtivos Industrializados: LSF. 2005. Dissertação (Mestrado em Engenharia Civil) - Escola de Minas, Universidade Federal de Ouro Preto, Ouro Preto, 2005.

FARAH, M. F. S. Processo de Trabalho na Construção Habitacional: tradição e mudança. São Paulo: Annablume, 1996.

FREIRE, J.; ALARCÓN, L. F. Achieving Lean Design Process: improvement methodology. Journal of Construction Engineering and Management, v. 128, n. 3, p. 251-261, may/jun. 2002.

GALLE, P. Candidate Worldviews For Design Theory. Design Studeis. v. 29, n. 3, p. 267-303, 2008.

GIUDICE, F.; BALLISTERI, F.; RISITANO, G. A Concurrent Design Method Based on DFMAFEA Tntegrated Approach. Concurrent Engineering: Research and Applications Journal, v. 17, n. 3, 2009.

GORGOLEWSKI, M. Developing a Simplified Method of Calculating U-Values in Light Steel Framing. Building and Enviroment, v. 42, n. 1, p. 230-236, 2006.

HOWELL, G.; BALLARD, G. Design of Construction Operations. In: Lean Construction Institute Implementation Workshop, Portland, 1999. Proceedings... Portland, 1999. LCI White Paper-4.

JØRGENSEN, B. Integrating Lean Design and Lean Construction: processes and methods. Denmark, 2006. Thesis (Doctor of Philosophy) The Technical University of Denmark, The Department of Civil Engineering, Denmark, 2006.

KHAN, Z. Design For Assembly. Assembly Automation Journal, v. 28, n 3, p. 200-206, 2008.

KOSKELA, L. Application of the New Production Philosophy to Construction. Stanford, EUA, ago. 1992. Technical Report No 72. 
KOSKELA, L. An Exploration Towards a Production Theory and Its Application to Construction. Espoo: VTT Publications, 2000. Technical Research Centre of Finland, n. 408.

KOSKELA, L.; HUOVILA, P.; LEINONEN, J. Design Management in Building Construction: from theory to practice. Journal of Construction Research, Finland, v. 3, n. 1, p. 1-16, mar. 2002.

KOSKELA, L. Foundations of Concurrent Engineering. In: ANUMBA, C.; KAMARA, J.; DECELLE, A.-F. C. (Eds.). Concurrent Engineering in Construction Projects. London: Taylor \& Francis, 2007.

KRUGLIANSKAS, I. Engenharia Simultânea: organização e implantação em empresas brasileiras. Revista de Administração, São Paulo, v. 28, n. 4, p. 104-110, 1993.

KUO, T.-C.; HUANG, S. H.; ZHANG, H.-C. Design For Manufacture and Design For " $X$ ": concepts, applications and perspectives.

Computers and Industrial Engineering, v. 41, n. 3, p. 241-260, 2001.

LAI, X.; GERSHENSON, J.K. Representation of Similarity and Dependency For Assembly Modularity. The International Journal of Advanced Manufacturing Technology, v. 37, n. 7/8, p. 803-827, 2008.

MOTTONEN, M. et al. Managerial View on Design For Manufacturing. Industrial Management and Data Systems Journal, v. 109, n. 6, p. 859-872, 2009.

PRINS, M.; KRUIJNE, K. The Management of Design Process Integration and Design Integration. In: CIB W096 Architectural Management; CIB TG49 Architectural Engineering Conference; BRAZILIAN WORKSHOP ON BUILDING DESIGN MANAGEMENT, 8., São Paulo, 2008. Proceedings... São Paulo, 2008.

SCUR, A. R. Aplicação do Design for Assembly (DFA) no Desenvolvimento do Projeto Conceitual de Um Dispositivo Funcional. Porto Alegre, 2009. Dissertação (Mestrado) - Escola de Engenharia, Universidade Federal do Rio Grande do Sul, Porto Alegre, 2009.
SONG, L.; MOHAMED, Y.; ABOURIZK, S. M. Early Contractor Involvement in Design and Its Impact on Construction Schedule Performance. Journal of Management in Engineering, v. 25, n. 1, p. 12-20, 2009.

STEHN, L.; BERGSTÖM, M. Integrated Design and Production of Multi-Story Timber Frame Houses: production effects caused by customeroriented design. International Journal of Production Economics, v. 77, n. 3, p. 259-269, 2002.

TSAO, C. C. Y. Use of Work Structuring to Increase Performance of Project-Based Production Systems. Berkeley, 2005. Dissertation (Doctor of Philosophy) - University of California, Berkeley, 2005.

VELJKOVIC, M.; JOHANSSON, B. Light Steel Framing For Residential Buildings. Thin-Walled Structures, v. 44, n. 12, p. 1272-1279, 2006.

VIVAN, A. L. Projetos Para Produção de Residências Unifamiliares em Light Steel Framing. São Carlos, 2011. Dissertação (Mestrado em Engenharia Civil) - Escola de Engenharia, Universidade Federal de São Carlos, São Carlos, 2011

VIVAN, A. L.; PALIARI, J. C. Comparação Entre Aspectos Produtivos de Edificações em Light Steel Framing e Alvenaria Estrutural. In: ENCONTRO TECNOLÓGICO DA ENGENHARIA CIVIL E ARQUITETURA, 8., Maringá, 2011. Anais... Maringá, 2011.

VIVAN, A. L.; PALIARI, J. C.; NOVAES, C. C. Vantagem Produtiva do Sistema Light Steel Framing: da construção enxuta à racionalização construtiva. In: ENCONTRO NACIONAL DE TECNOLOGIA DO AMBIENTE CONSTRUÍDO, 13., Canela, 2010. Anais... Porto Alegre: ANTAC, 2010.

WU, T.; O'GRADY, P. A Concurrent Engineering Approach to Design For Assembly. Concurrent Engineering: Research and Applications Journal, v. 7, n. 3, p. 231-243, 1999.

Revista Ambiente Construído

Associação Nacional de Tecnologia do Ambiente Construído

Av. Osvaldo Aranha, $99-3^{\circ}$ andar, Centro

Porto Alegre - RS - Brasil

CEP 90035-190

Telefone: +55 (51) 3308-4084

Fax: +55 (51) 3308-4054

www.seer.ufrgs.br/ambienteconstruido

E-mail: ambienteconstruido@ufrgs.br 